\title{
Agrotóxicos: nuevos y viejos desafíos para la salud colectiva
}

\author{
Agrotoxins: new and old challenges \\ for collective health
}

Los mecanismos de explotación de la naturaleza y de los seres humanos, y sus consecuencias para la salud y para el ambiente, son temas recurrentes y siempre actuales. Sin embargo, las cuestiones de salud pública que tienen su origen en el uso de agrotóxicos, a pesar de las evidencias de su nocividad, crecen a una escala insostenible, especialmente en América Latina. La producción monopólica y exportadora de los commodities agrícolas con base en un modelo químico y biotecnológico dependiente elevó a un nivel intolerable esa política nociva para la vida.

El agronegocio se instaló en nuestros países corrompiendo las estructuras políticas, económicas y sociales. Brasil, por ejemplo, desde 2009 es el mayor consumidor de agrotóxicos del mundo: adquiere el $84 \%$ de los agrotóxicos vendidos a América Latina (1). Las mayores empresas productoras de estos venenos, tales como BASF, Bayer, Syngenta/AstraZeneca/Novartis, DuPont, Monsanto y Dow, se instalaron en el país gracias a una política dirigida a proteger los intereses del agronegocio y de las bancas ruralistas en el parlamento brasileño, que paradójicamente apoyan a un gobierno que había propuesto hacer cambios estructurales, tales como la reforma agraria, que hasta ahora no se produjeron. A través de sus empresas, EE.UU., Suiza y Alemania, en conjunto, controlan el 70\% de la venta de agrotóxicos a Brasil (1). La venta mundial de agrotóxicos (en dólares) tuvo un incremento del 53,8\% desde 1990 a 2008 (1).

En 1976, en plena dictadura militar, se lanzó en Brasil la Política Nacional de Defensa Agrícola, que obligaba al agricultor a utilizar parte del crédito rural para la compra compulsiva de venenos. Rápidamente, en menos de 40 años, se instauró la hegemonía de la producción dependiente de agrotóxicos. En la actualidad, solo los movimientos de apoyo a la agroecología y a la agricultura orgánica luchan por mantener el saber milenario de la producción agrícola, buscando proteger los suelos, las aguas, la biodiversidad, la cultura de las poblaciones tradicionales, con respecto a las condiciones climáticas y al mejoramiento de las semillas.

Existe un verdadero estado de excepción relacionado al marco jurídico-institucional que sustenta las prácticas abusivas por parte del agronegocio. Si bien se han conquistado derechos y normas específicos para regular la producción y el consumo de agrotóxicos, existe una gran cantidad de enmiendas a la legislación que las tornan inoperantes, vulnerabilizando las instituciones y flexibilizando su uso en la práctica (2).

La escala gigantesca de la producción agrícola monopólica actual se da también a costa de insumos hidroenergéticos intensivos, a través de la expansión territorial sobre áreas de preservación natural, la destrucción de la agricultura familiar y la expulsión de poblaciones campesinas. Este contexto ha acarreado una situación nunca antes vivenciada en nuestra historia.

La tecnociencia desarrollada con recursos públicos en nuestras universidades e institutos de investigación se coloca al servicio de la acumulación capitalista del agronegocio, como también lo hace 
la formación profesional, bajo la creencia (ideología) de que es imposible producir sin estos insumos químicos y biotecnológicos.

Vemos con toda evidencia cómo están asociadas la reproducción social y la salud en ese modelo insustentable de producción. La agricultura milenariamente siempre tuvo un sentido positivo frente a la vida, armonizando la biodiversidad con las necesidades humanas de alimentos. El uso de los biocidas desarrollados en la Primera y Segunda Guerra Mundial, especialmente a partir de la década de 1970, sustentado por el discurso ideológico de un recurso tecnológico indispensable para solucionar los problemas del hambre, emerge dentro de un modelo económico globalizante de la agricultura denominado "Revolución Verde". Ese mismo discurso se repite ahora en defensa de la biotecnología transgénica para la producción de commodities agrícolas destinados a la industria alimentaria, al agrocombustible y al monopolio de las semillas (3).

Otra amenaza más reciente es la utilización de residuos industriales contaminados con metales pesados para la producción de micronutrientes utilizados en la agricultura. Parece increíble, pero esta es una amenaza concreta en Brasil, dado que está por ser publicada una resolución del Ministerio de Medio Ambiente en la que se establecen los niveles de tolerancia aceptables de contaminantes en esos residuos para ser utilizados en la producción de fertilizantes agrícolas (4).

La presencia de agrotóxicos ha sido observada en aguas superficiales y subterráneas, en el agua de Iluvia $(5,6)$ y en la atmósfera, incluso en zonas distantes de áreas agrícolas $(7,8)$. Hasta en la nieve del ártico (9) y en la niebla oceánica ha sido detectada (10).

En la principal región brasileña productora de soja transgénica (Mato Grosso), con uso intensivo del herbicida glifosato, entre otros agrotóxicos, ha sido encontrada una intensa contaminación ambiental y humana. Allí crece la preocupación por la contaminación de la mayor reserva de agua subterránea de América del Sur: el Acuífero Guaraní, ubicado entre las fronteras de Brasil, Paraguay, Uruguay y Argentina. Un estudio realizado en diversas nacientes oriundas de este acuífero han revelado contaminación por agrotóxicos (11). En un reciente estudio realizado en la Universidade Federal de Mato Grosso fueron encontrados residuos agrotóxicos en la leche materna (12).

La aplicación aérea de herbicidas por medio de aeronaves contamina ciudades y perjudica la producción de los pequeños agricultores de hortalizas, como es el caso de la ciudad de Lucas do Rio Verde, en Mato Grosso, Brasil (6).

Aunque estemos frente a un contexto adverso para la vida, el sistema de salud pública aún no actúa enérgicamente para poner bajo vigilancia a las poblaciones vulnerables a estas tecnologías, una demostración obvia de que también la salud pública está sometida a los dictámenes del modelo de desarrollo orientado a la acumulación capitalista (13).

Aún existe un importante subregistro del número de casos de intoxicaciones agudas y crónicas por exposición a los agrotóxicos. En la mayoría de las escuelas de medicina no se enseña a hacer diagnóstico, tratamiento y vigilancia de estos daños y los sistemas de vigilancia epidemiológica hacen poco para ampliar la detección y la investigación de estos agravios. Tampoco se integran a otros niveles de cuidados y otros sectores para las medidas de promoción y protección de la salud.

Esta desconsideración de la mayoría de los sistemas de salud públicos latinoamericanos por las problemáticas sanitarias y ecológicas derivadas del uso de los agrotóxicos no se restringe a la producción agrícola, a la seguridad alimentaria y a la calidad del agua para abastecimiento humano. Se extiende además al uso abusivo de la propia salud pública en el control de endemias vectoriales.

Identificamos una serie de errores injustificables, por ejemplo, en el modo de realizar el control del vector del dengue (Aedes aegypti). A pesar del uso masivo de organofosforados y de otros productos biocidas utilizados, y de la endemicidad de la enfermedad con recurrentes brotes epidémicos, la expansión vectorial es testimonio de la ineficacia de los reiterados programas que siguen una doctrina extranjera colonizadora, que aún ve nuestros territorios como "tropicales", una coartada más para endilgar el mismo modelo utilizado en la agricultura para el "combate" de las plagas. Un modelo que no considera las dinámicas ecosistémicas involucradas entre virus, vector y modos de vida de los seres humanos (14). 
Recientemente, la revisión del registro de once agrotóxicos que presentan efectos prohibitivos (mutagenicidad, carcinogenicidad, efectos sobre el sistema reproductivo y endócrino, sobre el desarrollo embrionario) reveló la fragilidad de los estudios presentados por las empresas interesadas, que son apenas de base experimental animal, en los que se busca la determinación de indicadores de efecto para después extrapolarlos a los humanos mediante un valor constante. Más allá de los vicios metodológicos observados, vemos cuán insuficientes son estos modelos que no consideran, entre otros condicionantes, las diferencias y especificidades de las especies e interacciones entre las diversas substancias y otras situaciones existentes en el modo de vida, de producción y consumo humano (15).

Los estudios epidemiológicos publicados son insuficientes y, con frecuencia, solo son de tipo transversal dado que son más baratos y no cuentan con el apoyo financiero para estudios de cohorte. Estos excluyen los elementos de la reproducción social en los macro y microcontextos aportando resultados poco aplicables a la determinación social como nos enseñaron Breilh (16), Samaja (17) y Castellanos (18).

El modelo científico hegemónicamente utilizado por las ciencias agrícolas y de la salud sigue su curso reduccionista, y las políticas engendradas por ellas ignoran la incertidumbre y la complejidad de los procesos involucrados en la interacción de esos objetos híbridos de naturaleza y cultura.

Al reducir el modelo de investigación a una linealidad de tipo causa-efecto, cuyos resultados solo benefician al capital monopólico, se producen injusticias ambientales que vulneran los derechos a la vida saludable y al ambiente salubre de las poblaciones.

Recientes investigaciones de cuño participativo, y de base epistemológica constructivista y compleja, han empoderado al movimiento social para la lucha de resistencia al modelo morbígeno de la modernización agrícola (19).

El campo de la salud colectiva tiene un importante compromiso con esta causa al demostrar las vulnerabilidades, los daños a la salud y las inequidades sociales relacionadas con el modelo agrario químico y biotecnológico dependiente, al producir una crítica profunda al modelo de ciencia que sustenta las decisiones en el ámbito de las políticas, en especial, las de salud pública, y al proponer otros modelos de estudios que consideren la complejidad de los problemas de salud colectiva y las acciones preventivas para la protección de la salud.

Augusto, Lia Giraldo da Silva

Médica. Doctora en Ciencias Médicas. Docente permanente, Programa de Pós-graduação em Saúde Pública, Fundação Oswaldo Cruz (Fiocruz-Pernambuco). Profesora adjunta, Faculdade de Ciências Médicas, Universidade de Pernambuco, Brasil. giraldo@cpqam.fiocruz.br

\section{REFERENCIAS BIBLIOGRÁFICAS}

1. Pelaez V. Monitoramento do mercado de agrotóxicos [internet]. Brasília: Agência Nacional de Vigilância Sanitária; 2010 [citado 31 jul 2011]. Disponible en: http://portal.anvisa.gov.br/wps/wcm/connect/c4bdf280474591a e99b1dd3fbc4c6735/estudo monitoramento.p $\mathrm{df} ? \mathrm{MOD}=\mathrm{AJPERES}$

2. Maciel KLS. O uso de venenos na agricultura: a judicialização do conflito ambiental. [Dissertação de Mestrado]. Recife. Universidade Federal de Pernambuco; 2012. 
5. Funari E, Donati L, Sandroni D, Vighi M. Pesticide levels in ground water: value and limitations of monitoring. En: Vighi M, Funaru E, editors. Pesticide risk in groundwater. Boca Raton: CRC Press; 1995. p. 3-44.

6. Pignatti WA, Machado JMH, Cabral JF. Acidente rural ampliado: o caso das "chuvas" de agrotóxicos sobre a cidade de Lucas do Rio Verde MT. Ciência \& Saúde Coletiva. 2007; 12(1):105-114.

7. Grover R, Wolt JD, Cessna AJ, Schiefer HB. Environmental fate of trifluralin. Reviews of Environmental Contamination \& Toxicology. $1997 ; 153: 1-64$.

8. Laabs V, Amelung W, Pinto A, Wantzen M, Silva CJ, Zech W. Pesticides in surface water, sediment, and rainfall of the Northeastern Pantanal basin, Brazil. Journal of Environmental Quality. 2002;31(5):1636-1648.

9. Gregor DJ, Gummer WD. Evidence of atmospheric transport and deposition of organochlorine pesticides and polychlorinated biphenyls in Canadian artic snow. Environmental Science \& Technology. 1989;23(5):561-565.

10. Schomburg CJ, Glotfelty DE. Pesticide occurrence and distribution in fog collected near Monterey, California. Environmental Science \& Technology. 1991;25(1):155-160.

11. Estudo mostra que o Aqüífero Guarani está contaminado por agrotóxicos. Novoeste on-line [Internet]. 19 may 2011 [citado 7 mar 2011]. Disponible en: http://www.novoeste.com/ pages/news/pdf.php?id $=4464$

12. Palma DCA. Agrotóxicos em leite de mães residentes em Lucas do Rio Verde-MT. [Dissertação de Mestrado]. Cuiabá: Instituto de Saúde Coletiva, Universidade Federal de Mato Grosso; 2011.
13. Bombardi LM. Intoxicação e morte por agrotóxicos no Brasil: a nova versão do capitalismo oligopolizado. Boletim DATALUTA [Internet] 2011 [citado 9 mar 2012];sep. Disponible en: http://www2.fct.unesp.br/nera/artigodomes/9artigodomes_2011.pdf

14. Augusto LGS, Carneiro RM, Martins PH. Abordagem ecossistêmica em saúde: Ensaios para o controle de dengue. Recife: Editora Universitária; 2004.

15. Augusto LGS, Gurgel AM, Bedor CNG, Gurgel IGD, Friedrich K, Mello MSC, Siqueira MT. O contexto de vulnerabilidade e de nocividade do uso dos agrotóxicos para o meio ambiente e a importância para a saúde humana. En: Rigotto R. Agrotóxicos, trabalho e saúde: Vulnerabilidade e resistência no contexto da modernização agrícola no Baixo Jaguaribe/CE. Fortaleza: Edições UFC; 2011. p. 257-272.

16. Breilh J. Epidemiología crítica: ciencia emancipadora e interculturalidad. Buenos Aires: Lugar Editorial; 2003.

17. Samaja JA. Reprodução social e a saúde: elementos metodológicos sobre a questão das relações entre saúde e condições de vida. Salvador: Casa da Qualidade, ISC, UFBA; 2000.

18. Castellanos PL. Sobre el concepto de saludenfermedad: Descripción y explicación de la situación de salud. Boletín Epidemiológico. 1990;10(4):1-7.

19. Rigotto R. Agrotóxicos, trabalho e saúde. Vulnerabilidade e resistência no contexto da modernização agrícola no Baixo Jaguaribe/CE. Fortaleza: Edições UFC; 2011.

\section{FORMA DE CITAR}

Augusto LGS. Agrotóxicos: nuevos y viejos desafíos para la salud colectiva [Editorial]. Salud Colectiva. 2012;8(1):5-8. 